\title{
ESTUDIO DE LOS ESTRENOS TEATRALES DE ENRIQUE JARDIEL PONCELA Y MIGUEL MIHURA EN LAS CRÓNICAS DE FERNANDO LÁZARO CARRETER
}

\author{
Laura Arroyo Martínez \\ Universidad Complutense de Madrid
}

A Luis Martínez-Falero

\begin{abstract}
RESUMEN
El presente trabajo tiene como principal objetivo describir y analizar las reseñas periodísticas que Fernando Lázaro Carreter publicó en las páginas de Gaceta ilustrada y de Blanco y Negro sobre los estrenos de las obras de Enrique Jardiel Poncela y de Miguel Mihura, dramaturgos creadores de una nueva forma de hacer comedia en las primeras décadas del siglo pasado. Para ello, describimos el contenido de las mismas y lo cotejamos con las crónicas escritas por otros especialistas, para poder entenderlas y valorarlas dentro del contexto teatral del momento. El conocimiento de estos materiales permite descubrir una faceta del célebre filólogo mucho menos estudiada por los especialistas, pero que a su vez encierra un valor muy importante para el conocimiento del funcionamiento de nuestro teatro en democracia. Palabras Clave: Lázaro Carreter, crítica teatral, Jardiel Poncela, Miguel Mihura
\end{abstract}

Recibido: 02-05-2014 / Aceptado: 11-08-2014 
Abstract

The main objective of this paper is to describe and to analyse the reviews that Fernando Lázaro Carreter published within the Gaceta Ilustrada's and Blanco y Negro's pages on the releases of the plays by Jardiel Enrique Ponce and by Miguel Mihura who were creators of a new form of making comedy in the early decades of the last century. Hence, we describe herein the contents of these reviews and we cross-check them with the reviews by other specialists in order to understand and assess them within the theatrical context of the moment. The insight given by the study of these materials leads to discover a not so studied aspect of the renowned philologist, although it had a significant worth for working out the democracy of our theater.

KEY WORDS: Lázaro Carreter, theater criticism, Jardiel Poncela, Miguel Mihura

\section{INTRODUCCIÓN}

La labor filológica, investigadora y docente de Fernando Lázaro Carreter (19232004) le han convertido en una figura de primer nivel en el ámbito humanístico del siglo pasado en nuestro país. Su obra destaca por su rigor científico y su amplitud temática. Sus estudios poseen plena vigencia en la actualidad y se han convertido, por méritos propios, en un referente clásico en los estudios literarios y lingüísticos. Su legado ha abierto caminos en campos de investigación como la Crítica literaria, la Teoría de la literatura y la Lingüística. Su magisterio ha marcado a generaciones de estudiantes y filólogos que conocen y respaldan su obra. Actualmente, algunos estudios críticos que describen y analizan la obra de Fernando Lázaro Carreter están viendo la luz $\mathrm{y}$, afortunadamente, estas aportaciones académicas ${ }^{1}$ nos ayudan a continuar manteniendo vivo este importante caudal de conocimiento e impidiendo su olvido dentro de los estudios de Historia de la Crítica.

Además de su obra científica y pedagógica, Lázaro Carreter publicó durante varios años una amplia nómina de crónicas periodísticas centradas en diversos temas teatrales. Estas reseñas se publicaron en la revista Gaceta ilustrada entre 1972 y 1981 y en la revista Blanco y Negro entre 1988 y 1992 con una periodicidad semanal. Estas publicaciones de divulgación fueron escritas para llegar a un público general, no especializado, aficionado al teatro, pero a la vez proporcionaban el juicio de un experto sobre temas tan diversos como la crisis del teatro, las publicaciones de obras de diversos autores y, principalmente, los estrenos de cartelera, tanto de autores españoles, como extranjeros. Estos textos nos aportan un valioso conocimiento sobre la vida teatral de estos años, así como de las obras y autores que estrenaron, siempre bajo la mirada de

\footnotetext{
1 A este respecto hay que destacar la importancia del artículo de Túa Blesa «Fernando Lázaro Carreter: la literariedad de la literatura» (2008) en el que se realiza una panorámica de lo que han supuesto los estudios de Fernando Lázaro para la Filología moderna. Del mismo modo, como estudio de conjunto a la labor crítica del crítico aragonés encontramos la Tesis doctoral titulada Crítica literaria y creación teatral en Fernando Lázaro Carreter (Universidad Complutense de Madrid, 2013). Ambos trabajos citados en la bibliografía del presente artículo.
} 
un crítico de la intuición, sabiduría y personalidad de Lázaro Carreter, que consiguió un público extenso.

Este artículo se centra en analizar las crónicas que Lázaro Carreter publicó sobre los estrenos de las obras de Enrique Jardiel Poncela (1901-1952) y de Miguel Mihura (1905-1977). Por lo tanto, en estas páginas vamos a poder analizar cuáles fueron los juicios que don Fernando realizó sobre los estrenos teatrales de estos dos dramaturgos, fundamentales para nuestro teatro humorístico de la primera mitad del siglo $X X$, al que aportaron una importantísima renovación. Del mismo modo, sintetizaremos su valoración general sobre la trayectoria de los mismos; valoración en algunas ocasiones discrepante respecto a ciertas tesis defendidas tradicionalmente por los especialistas. ${ }^{2}$ No cabe duda de que el humorismo de los creadores de «la otra» Generación del 27, sus características y sus fundamentos fue un asunto que atrajo el interés de Lázaro Carreter. En las páginas que continúan, por tanto, nos proponemos descubrir estas ideas, insertas en el excepcional marco de sus crónicas periodísticas, muy populares en el momento que vieron la luz, pero poco estudiadas académicamente en los últimos años.

\section{Crítica a los estrenos de Enrique Jardiel Poncela (1901-1952)}

La crítica especializada divide tradicionalmente la trayectoria de Jardiel Poncela en dos etapas claramente diferenciadas: antes y después de la guerra civil. Su primera obra fue Una noche de primavera sin sueño (1927), a la que seguirán otros siete títulos antes del inicio del conflicto bélico: Usted tiene ojos de mujer fatal (1933), Angelina y el honor de un brigadier (1934), Las cinco advertencias de Satanás (1935), Un adulterio decente (1935) y Cuatro corazones con freno y marcha atrás (1936), obra con la que su carrera «alcanza su primer punto de madurez interna, constituyendo la primera muestra de ese teatro de lo inverosímil que desde el comienzo había venido persiguiendo» (Ruiz Ramón 269). Al terminar la guerra escribirá otros veinte títulos, entre los que destacan: Un marido de ida y vuelta (1939), Eloísa está debajo de un almendro (1940), Los ladrones somos gente honrada (1941), Los habitantes de la casa deshabitada (1942), Blanca por fuera y

\footnotetext{
2 Como se va a comprobar en las siguientes páginas de este artículo, Lázaro Carreter mostró gran interés en descartar la utilización de la etiqueta «teatro del absurdo» para emplearla en nuestros dramaturgos cómicos de posguerra, puesto que no admite la comparación con la tendencia europea del teatro del absurdo. Sin embargo, hoy podemos seguir encontrando una parte de la crítica especializada que utiliza este término y estas ideas. Tal es el caso del espléndido trabajo de revisión sobre teatro cómico realizado por la profesora María Luisa Bruguera: «El teatro cómico: de Jardiel a Paso», publicado en Historia del teatro español, II, incluido también en la bibliografía final.

3 Referencia inexcusable para comprender el humorismo en la que se conoce como «la otra» generación del 27 es el discurso leído por José López Rubio en su ingreso en la Real Academia Española. En dicho texto desgrana las claves de este grupo de dramaturgos que reinventaron una manera de hacer humor en nuestro país. Se puede encontrar la referencia completa en la bibliografía.
} 
rosa por dentro (1943), Tú y yo somos tres (1945) o, su última obra, Los tigres escondidos en la alcoba (1949). ${ }^{4}$

Además de su obra dramática, no se puede obviar su faceta como novelista, pese a que su producción narrativa haya recibido una menor atención por parte de los especialistas. Sus novelas están cargadas con su peculiar y divertidísimo humor. Sus títulos principales son: Amor se escribe sin hache (1929), Espérame en Siberia, vida mía (1930), Pero... ¿hubo alguna vez once mil vírgenes? (1931) y La tournée de Dios (1932), obras en las que también disfrutamos con la muestra de su gran talento y de su inmensa inteligencia cómica. ${ }^{5}$

Lázaro Carreter publicó cuatro reseñas sobre los estrenos de Jardiel Poncela. Tan solo fueron dos los estrenos de obras de Jardiel que Lázaro Carreter reseñó en las páginas de Gaceta Ilustrada. El primero de ellos fue el de Angelina o el honor de un brigadier, el veinte de febrero de 1979 en el Centro Cultural de la Villa de Madrid. La obra fue llevada a los escenarios por primera vez en 1934, es decir, en una etapa de consolidación de la dramaturgia jardielesca. La pieza es para Lázaro Carreter un clásico, menor, claro está, pero alcanza tal estatus y, por esa razón, sigue conservando su éxito, pese a haber sufrido con dureza los estragos del paso de los años sobre el efecto de su comicidad. En este aspecto sí debemos tener presente que esto no es un lastre específico de esta obra, ni del conjunto de obras de Jardiel. El teatro humorístico sufre de manera muy especial este envejecimiento, que puede palparse incluso en clásicos mayores como La venganza de don Mendo, estrenada en 1928.

Pese a ello, don Fernando considera una evidencia incuestionable que si el texto jardielesco «ha resistido el paso del tiempo es porque posee cualidades que no eran circunstanciales hace nueve lustros. A cambio, al no contar con más plano de referencia que ella misma, tal vez ha sufrido bastante pérdida de comicidad. ${ }^{6}$ Ante esta situación, que tenemos que admitir, el crítico califica el estreno de 1979 como «piececita de Pascuas, que atrae, más que por sí misma, por las circunstancias en que se representa y por el cariño que suscita la memoria de su autor.» ${ }^{7}$ Es decir, según su

\footnotetext{
${ }^{4}$ Se puede tomar como referencia para la clasificación de las obras la correspondiente entrada del autor en la obra Teatro español: de la A a la Z, Madrid, Espasa Calpe, 2005.

5 Para obtener una valoración seria y extensa de las novelas de Jardiel Poncela, que permite entender a la perfección las claves del humor del escritor madrileño, el lector debe consultar las introducciones críticas de las siguientes ediciones, cuya referencia completa se encuentra en la bibliografía final: Pero... ¿hubo alguna vez once mil vírgenes?, ed. Luis Alemany, Madrid, Cátedra, 2007 y Amor se escribe sin hache, ed. Roberto Pérez, Madrid, Cátedra, 2006.

6 F. Lázaro Carreter, «Angelina o el honor de un brigadier», Gaceta ilustrada, (11 de febrero de 1979), p. 52.

7 F. Lázaro Carreter, «Angelina o el honor de un brigadier», Gaceta ilustrada, (11 de febrero de 1979), p. 52.
} 
criterio, la nostalgia del espectador es la que hace alcanzar el aplauso del público y no el texto en sí mismo.

El segundo estreno de Jardiel al que Lázaro Carreter prestó atención fue el de Una noche de primavera sin sueño. Se presentó sobre los escenarios en el teatro Lara el 17 de abril de 1979. Fue dirigida por Zacarías Urbiola e interpretada por María Elías, Ana Frau, Valeriano Andrés y Ricardo Merino, entre otros. Con plena razón, Lázaro Carreter cuestionó la elección de este título entre toda la obra del humorista madrileño. El profesor, a lo largo del recorrido de sus crónicas, muestra una gran preocupación ante el hecho de que siempre se estrenen obras de otras épocas, de otros tiempos, a la vez que se dan oportunidades mínimas, casi inexistentes, a las nuevas dramaturgias. A esta preocupación, en el caso concreto de los estrenos de Jardiel Poncela, sumó sin reparos el poco acierto en la elección de cierta parte de su obra para ser llevada a las tablas. Como hemos explicado, Una noche de primavera sin sueño es su primera obra y en ella todavía no mostró la maestría que tendría su teatro posterior. Era una obra de iniciación, todavía inmadura en algunos aspectos. A este respecto, Lázaro Carreter se hizo la siguiente pregunta: «¿Por qué no se eligen sus comedias mayores? Si se trata -y de eso se trata, seguramente- de hacer cosas baratitas y sencillas bajo el amparo de un nombre de crédito, se va a acabar pronto con el nombre y con el crédito.» ${ }^{8}$ Para don Fernando, estamos ante una obra que ha quedado anticuada y que no representa, en modo alguno, la importancia del talento dramático de Jardiel, al descubrir un título incipiente en su recorrido. La mayoría de la crítica coincidió en señalar este desacierto a la hora de seleccionar el texto de Jardiel. Según Ángel Fernández Santos,

la elección de esta obra es totalmente inadecuada para una revisión útil y real de Jardiel, cuando para la inmensa mayoría de los espectadores permanecen prácticamente inéditas comedias como Un marido de ida y vuelta, Eloísa está debajo de un almendro, Un adulterio decente y tantas otras más que dan verdadera idea del talento de aquel hombre. ${ }^{9}$

De manera similar razonó Pablo Corbalán, para quien «nos encontramos [...] en los balbuceos de Jardiel. Se percibe su talento, pero como balbuceo.» ${ }^{10}$ Por tanto, Lázaro Carreter concluyó que no se trata con la justicia necesaria y exigible al autor si se lleva a las tablas una comedia que «es sólo un momento de paso en la esforzada carrera de Jardiel, que cuajará en los alrededores de la guerra civil, sobre todo tras ésta.» ${ }^{11}$

Encontramos algunos críticos que razonaron de manera diferente y para los que la comedia sí poseía méritos suficientes para ser representada. Según la mirada

\footnotetext{
8 F. Lázaro Carreter, «Una comedia de Jardiel», Gaceta ilustrada, (3 de junio de 1979), p. 74.

9 F. Álvaro, El espectador y la crítica. El teatro en España en 1972, Madrid, Prensa española, 1980, p. 54.

10 F. Álvaro, El espectador y la crítica. El teatro en España en 1972, Madrid, Prensa española, 1980, p. 55.

11 F. Lázaro Carreter, «Una comedia de Jardiel», Gaceta ilustrada, (3 de junio de 1979), p. 74.
} 
de Julio Trenas, «todo el teatro de Jardiel, incluida Una noche de primavera sin sueño, mantiene su vigencia con proyección de novedad respecto a algunas obras de hoy. Las comedias de Jardiel no precisan de arreglos, adaptaciones y retoques.» ${ }^{12}$ Para Manuel Díez Crespo,

su diálogo y situaciones se mantienen frescas. Esto es lo importante y hay que subrayarlo, porque hoy es posible que algunos no lleguen a darse cuenta de lo que representa esta pieza como arranque de otras formas que habrían de dar mucho juego en años posteriores. ${ }^{13}$

Por tanto, otra parte de los especialistas mantenía una posición contraria a Lázaro Carreter. Nosotros consideramos, al igual que don Fernando y otros críticos, que Una noche de primavera sin sueño no es la obra más apropiada para dar a conocer la labor literaria de Jardiel a un público mayoritario, al ser una obra de iniciación, sin negar que en el texto se encierren las claves que el escritor desarrollará en años posteriores. ${ }^{14}$

Según Lázaro Carreter, ni siquiera la representación, en este caso, puede hacer levantar el vuelo a una comedia de segundo nivel. Con duras palabras el crítico finalizó su crónica:

Puesto que estamos en mes de exámenes, califiquemos la función del Lara: no más de cuatro (sobre diez) [...]. Porque, en general, los actores, con el director al frente, son víctimas de un naufragio cuya contemplación hiela la sangre. La falta de fe más absoluta, el oficio rutinario, el trámite como método presiden esta representación de Jardiel, cuyos motivos últimos no logro entender. ${ }^{15}$

De este modo, Lázaro Carreter cierra su comentario poniendo nuevamente en entredicho un problema grave de las carteleras del momento ( $\mathrm{y}$, por desgracia, todavía de actualidad), al que hará referencia en múltiples ocasiones. Este no es otro que el hecho de condenar el estreno de determinadas obras que, por cuestiones diversas, ponen en riesgo el prestigio y la salud de nuestro teatro y que se estrenan, en multitud de ocasiones, por motivaciones comerciales, muy alejadas de las puramente literarias.

Usted tiene ojos de mujer fatal se estrenó en el teatro Maravillas el 23 de mayo de 1989. Fue dirigida por Mara Recatero e interpretada por Fernando Delgado, Víctor

12 F. Álvaro, El espectador y la crítica. El teatro en España en 1972, Madrid, Prensa española, 1980, p. 54.

13 F. Álvaro, El espectador y la crítica. El teatro en España en 1972, Madrid, Prensa española, 1980, p. 54.

14 Como explica Francisco Javier Sahuquillo, «Jardiel, ya en 1927, era consciente de la crisis que se abatía sobre la escena española. [...] Poncela asumía que el humor se llevaba a las novelas o a los artículos de revista pero que se hallaba ausente en el espacio escénico. Es entonces cuando adquiere una voluntad renovadora», p. 3. Entonces, «un joven Jardiel de 25 años imagina un cambio de rumbo, con el que la juventud de entonces intente llevar a aquel pobre teatro espíritu, gracia noble, emoción pura, poesía verdadera e interés legítimo», p. 4

15 F. Lázaro Carreter, «Una comedia de Jardiel», Gaceta ilustrada, (3 de junio de 1979), p. 74. 
Valverde, María Kosty y Mary Begoña, entre otros. A Lázaro Carreter no le agradó la selección de esta obra para ser estrenada puesto que, como destacó:

Realmente, no se equivocaba el autor al calificarla de vieja en 1938. [...] El tiempo no la ha rejuvenecido, y lo que hoy esperan del humor los espectadores más alertados ha de ser, necesariamente, más complejo e inventivo, estrenados como están por el propio Jardiel en obras posteriores mucho más densas de invención, y, sobra decirlo, por otras fórmulas humorísticas que se han ido sucediendo en escenarios y en pantallas, y también en libros, revistas, etcétera, a lo largo del medio siglo último. ${ }^{16}$

Por tanto, la obra no debería de cosechar, según su criterio, el éxito que obtuvo con su montaje en el teatro Maravillas:

El humor de Usted tiene ojos de mujer fatal padece hoy de suma elementalidad. Pero existe aún un público que sigue riéndose con sus inocentes y vetustas graciosidades. Celebraría que fuera abundante, para premiar la lealtad de los intérpretes y de los rectores del teatro Maravillas a Jardiel Poncela. Mucho más numeroso, incluso, que el que se ríe con comedias americanas reseñadas aquí últimamente. ${ }^{17}$

Eduardo Haro Tecglen coincidió con Fernando Lázaro en señalar que el público al que encandiló el estreno era un público mayor, familiarizado con unas fórmulas teatrales de otros tiempos:

Queda como una muestra de lo que comenzaba a ser el nuevo teatro cómico en su tiempo y del sentido del humor que Poncela aportaba a algo que se anquilosaba; y puede satisfacer a antiguos espectadores que no se encuentran a gusto con los intentos de teatro cómico actuales, muchos de ellos remedos de la grandeza de Poncela y viven a su costa sin llegar a su genio. ${ }^{18}$

La valoración de Antonio A. Gómez Yebra en su edición de la obra en la editorial Castalia se distancia notablemente de la de Lázaro Carreter. Para Gómez Yebra la comedia es importante en la trayectoria del humorista madrileño, puesto que

[s]in ser genial, la obra se puede considerar entre las más dignas de Jardiel por cuanto le supuso un enorme esfuerzo para incorporarle novedades respecto a la novela, por cuanto hizo y aún hace reír al espectador, y por la calidad de la mayor parte de sus diálogos. En cuanto a la construcción de la obra misma y a los procedimientos para hacer reír, deja más que desear, como el propio Jardiel constató. ${ }^{19}$ (Gómez Yebra 1990, 57)

Respecto al estreno reseñado por Lázaro Carreter, también Beatriz Cortázar se mostró mucho más complaciente:

\footnotetext{
16 F. Lázaro Carreter, «Usted tiene ojos de mujer fatal, de Jardiel Poncela», Blanco y Negro, (9 de julio de 1989), p. 12.

17 F. Lázaro Carreter, «Usted tiene ojos de mujer fatal, de Jardiel Poncela», Blanco y Negro, (9 de julio de 1989), p. 12.

18 E. Haro Tecglen, «El principio de algo», El País, (25 de mayo de 1989), p. 87.

19 E. Jardiel Poncela, Usted tiene ojos de mujer fatal; Angelina o el honor de un brigadier, A. A. Gómez Yebra (ed.), Madrid, Castalia, 1990.
} 
Divertida como la que más, entrañable para un público sensible y fiel a Jardiel Poncela, y con unas interpretaciones que de nuevo demuestran el buen hacer de nuestros actores, Usted tiene ojos de mujer fatal es una oportunidad única para comprobar hasta dónde llegan los límites del amor y pasar un buen rato con esta comedia de tan buen gusto. ${ }^{20}$

El 16 de diciembre de 1987 se estrenó en el teatro Maravillas una vez más Cuatro corazones con freno y marcha atrás. Fue dirigida por Mara Recatero e interpretada por José Sazatornil, Rafaela Aparicio y Luis Varela, entre otros. Como explicó Carlos Galindo $(A B C)$,

la paulatina recuperación de los textos de Enrique Jardiel Poncela se convierten en rotundos éxitos de público. Sus textos, a pesar de los años, siguen vigentes, llenos de frescura, aunque fueran escritos para otros públicos, otras mentalidades. Pero aquí están sus obras con elementos de parodia y de gran guiñol y el espíritu personalísimo que supo darles. ${ }^{21}$

En relación a la situación del texto en la trayectoria del dramaturgo, Lázaro Carreter advirtió lo siguiente:

Cuatro corazones con freno y marcha atrás, aunque precede a las obras más ambiciosas de Jardiel, es ya un espécimen puro de ellas, un compendio de sus méritos y defectos. Aquéllos residen en lo perfecto del absurdo. Y no escribo «absurdo» sin temor; no acepto, ni de lejos, el tópico tan repetido de que tales obras -o algunas de Mihura y Tono- anticipan, joh, país de precursores!, lo que será luego el llamado «teatro del absurdo» (Ionesco, Beckett, Adamov...), el cual posee fundamentos filosóficos y estéticos que ni sospecharon nuestros supuestos pioneros. «Cuatro corazones...» es obra absurda en el sentido más común de la palabra; porque sus personajes irrumpen en el viaje inexorable hacia la vejez, se plantan en una edad frenando el paso del tiempo, y empiezan luego a retroceder en pos de la infancia. $^{22}$

Eduardo Haro Tecglen, vuelve a señalar lo anquilosado de los estrenos de Jardiel y la justificación del éxito sobre las tablas gracias a un fidelísimo público:

En el público del estreno se veían muchos rostros del teatro de antes, muchos inconmovibles jardielistas que le acompañaron en el via crucis de sus últimos años. Eran también corazones con marcha atrás, en busca de su tiempo perdido. Aplaudieron algunos mutis, los finales de acto, y tributaron al final sus ovaciones: una rosa roja en un símbolo de luz simbolizó al autor. ${ }^{23}$

Pese a esta antigüedad, Lorenzo López Sancho señala el gran aplauso del público que sigue teniendo la comedia:

20 B. Cortázar, «Usted tiene ojos de mujer fatal, un clásico de la seducción», ABC, (16 de junio de 1989), p.147.

${ }^{21}$ C. Galindo, «Cuatro corazones con freno y marcha atrás, nuevo pálpito de Jardiel Poncela», $A B C$, (15 de diciembre de 1987), p. 101.

${ }^{22}$ F. Lázaro Carreter, «Cuatro corazones con freno y marcha atrás», Blanco y Negro, (10 de abril de 1988), p. 12.

${ }^{23}$ E. Haro Tecglen, «Jardiel, marcha atrás». El País, (18 de diciembre de 1987), p. 85. 
Las nuevas generaciones de espectadores -ayer en la previa al estreno unos centenares de jóvenes estudiantes del Centro de Estudios Universitarios- la reciben con carcajadas en cadena, con bravos y aplausos en las frases más explosivamente cómicas con las que Jardiel dejó sembrado su texto como un campo de minas de la hilaridad. ${ }^{24}$

Fernando Valls y David Roas aprecian los logros del texto jardielesco, al que definen en los siguientes términos: «[e]s una de las obras más logradas de Jardiel, una de aquellas en las que mejor funciona su humor inverosímil, en la que logra integrar elementos clásicos y modernos para conseguir agradar al espectador y lograr sus propósitos de renovación teatral..$^{25}$ Sin embargo, no sucede lo mismo con su valoración sobre el estreno reseñado por Lázaro Carreter. En su introducción a la edición de Austral, critican duramente el estreno, señalando nuevamente su lado más obsoleto: «La puesta en escena es tan arcaica, como todas las que esta directora le ha dedicado a Jardiel, y su actualización del argumento difícilmente justificable.» ${ }^{26}$ Por consiguiente, comparten en lo fundamental la opinión de don Fernando. La crítica especializada sabe entender que el teatro jardielesco si triunfa hoy es, precisamente, por el gusto antiguo de gran parte de los espectadores.

Como se ha podido comprobar, Jardiel Poncela no es uno de los autores dilectos de don Fernando. Respeta sus logros literarios en relación a sus invenciones cómicas, y a sus innovaciones, pero no digirió en cierta medida los estrenos del escritor madrileño. Por tanto, podemos deducir de la lectura de sus crónicas que, según su criterio, es más un valor histórico de nuestras letras, pero difícilmente actualizable en nuestras tablas.

\section{Crítica a los estrenos de Miguel Mihura (1905-1977)}

Miguel Mihura fue uno de nuestros humoristas de posguerra más importantes. «Pertenece por la fecha de su primera obra a esa etapa de renovación del teatro español anterior a la guerra civil, etapa caracterizada por las múltiples rupturas de las formas y los temas dramáticos convencionales.» (Ruiz Ramón, 321) Su primera obra fue Tres sombreros de copa (1932), que tuvo que esperar veinte años para estrenar y a la que siguieron, entre los títulos más destacables, ;Viva lo imposible! o el contable de estrellas, en colaboración con Calvo Sotelo (1939), Ni pobre ni rico, sino todo lo contrario, en colaboración con Tono (1943), El caso de la mujer asesinadita, en colaboración con

24 L. López Sancho, «Cuatro corazones con freno y marcha atrás, kamikace cómico en el Maravillas», $A B C$, (18 de diciembre de 1987), p. 104.

25 E. Jardiel Poncela, Cuatro corazones con freno y marcha atrás; Los ladrones somos gente honrada, F. Valls y D. Roas (eds.), Madrid, Espasa Calpe, 2000, p. 47.

26 E. Jardiel Poncela, Cuatro corazones con freno y marcha atrás; Los ladrones somos gente honrada, F. Valls y

D. Roas (eds.), Madrid, Espasa Calpe, 2000, p. 48. 
Álvaro de Laiglesia (1946), El caso del señor vestido de violeta (1954), Melocotón en almíbar (1958), Maribel y la extraña familia (1959), La bella Dorotea (1963) o Ninette y un señor de Murcia (1964).

Como explicó Lázaro Carreter en un artículo homenaje tras el fallecimiento del autor, el estilo de esta nueva generación de humoristas, en la que se incluyen los nombres de Tono, Jardiel, Neville, López Rubio y el propio Mihura, bebe en fuentes europeas. El crítico puntualizó que

Mihura,-como toda su generación- estudió ese humor, al que estaba predestinado. De ese estudio; y de su genio personal, nació Tres sombreros de copa. Y, sin estrenarse la comedia, llegó nuestra guerra civil. Con La ametralladora, primero, y después con La codorniz, el país se empapó de aquel modo de escribir (y dibujar). ${ }^{27}$

Lázaro Carreter publicó un total de nueve reseñas sobre los estrenos de las obras de Miguel Mihura. El único estreno de Mihura que Lázaro Carreter analizó en G. I. fue el de Maribel y la extraña familia el uno de septiembre de 1978 en el teatro Infanta Isabel. Como recuerda Lázaro Carreter, el dramaturgo madrileño consideraba esta obra su mejor creación. ${ }^{28} \mathrm{El}$ crítico discrepa de tal juicio, pero lo justifica puesto que

es posible que, en su valoración, influyese el éxito que la obra obtuvo, y que en la escala de valores literarios resulte imposible otorgarle ese lugar. Pero lo cierto es que, en esas páginas, Mihura expresó su ideal humano con mayor explicitud que en ninguna otra, y que tal vez a ello se deba su preferencia. ${ }^{29}$

En relación al estreno y, sustentándolo en el éxito obtenido, Lázaro Carreter afirmó que muchas obras imperecederas lo son precisamente por la sencillez y transparencia de su mecanismo, entre las que se encuentra Maribel. Cierra su crónica de la manera más rotunda posible:

si a los veinte años de su estreno, tras haber dado la vida del país un vuelco impresionante en los valores $\mathrm{y}$ en los gustos, la gente sigue riéndose y conmoviéndose con una comedia que se ofrece sin ningún retoque, y le sigue subyugando su ingenio y la perfección de su arte, ello sólo puede significar que es una comedia clásica. ${ }^{30}$

27 F. Lázaro Carreter, «Miguel Mihura», Gaceta ilustrada, (11 de diciembre de 1977), p. 83.

28 Como reconoció el propio Miguel Mihura: «Era una comedia que me había salido con una exactitud cronométrica, y sin ninguna pieza que fallase. [...] Creo firmemente que Maribel ha sido mi obra más conseguida. Yo, al menos, estoy muy contento de haber escrito esta comedia» (Mihura, 1997, 53). Así también lo constata Jerónimo Mihura, hermano de Miguel Mihura en una entrevista concedida a Ángel Laborda en el momento de su estreno: «Esta fue una de las obras más queridas de mi hermano... y también uno de sus grandes éxitos de crítica y de público. Se estrenó el 29 de septiembre de 1959: el día de su santo. Y ha sido traducida a siete idiomas...» (Laborda 38).

29 F. Lázaro Carreter, «Maribel y la extraña familia de Miguel Mihura», Gaceta ilustrada, (1 de octubre de 1978), p. 65.

30 F. Lázaro Carreter, «Maribel y la extraña familia de Miguel Mihura», Gaceta ilustrada, (1 de octubre de 1978), p. 65. 
La decente de Miguel Mihura se estrenó el trece de mayo de 1988 en el teatro Infanta Isabel. Estuvo dirigida por Álvaro Sáenz de Heredia e interpretada por Vicente Parra, Mary Paz Pondal y Lola Lemos, entre otros. Como explicó Lázaro Carreter, «es, sin duda, una obra menor, pero sostenida con ese pulso limpio que siempre tenía la escritura de Mihura». ${ }^{31}$ La obra

tiene una trama policíaca, como Carlota, aunque de menor aliento. La intriga, más acentuadamente cómica, está cuidadosamente meditada, y podría haber servido para un relato serio, aunque de planteamiento poco original: una esposa trama el asesinato de su marido para poder casarse con otro. ${ }^{32}$

Por tanto, «la falta de originalidad es deliberada: se trata de construir un ámbito archiconocido en la narrativa de crímenes, una situación 'clásica', para inscribir en ella la absoluta anomalía de unos personajes entre disparatados y entrañables.» ${ }^{33}$ Respecto al estreno, Lázaro Carreter tampoco se mostró de acuerdo con la interpretación de los actores, puesto que, según su criterio, «el reparto rebaja su graduación y la enfría. Dudo de que Mihura imaginara una decente así de frívola, más propia de vodevil. [...] Sólo José María Escuer consigue algún ajuste con su personaje. ${ }^{34}$ Sin embargo, a pesar de que señaló que la representación demuestra que no se ha entendido correctamente a Mihura, no nos encontramos ante una condena directa del crítico, que se muestra generoso: «si mis lectores no saben dónde pasar la tarde, les recomiendo el Reina Victoria. Aunque haya que levantar algo la cabeza para verlo, allí está Miguel Mihura.» ${ }^{35}$

En este caso, otros especialistas dejaron patente su desacuerdo con el montaje de una manera mucho más explícita. Lorenzo López Sancho $(A B C)$ se mostró tajante en la condena del espectáculo: «Lástima de comedia. Mihura no hubiera dejado pasar la cosa del tercer ensayo. Álvaro Sáenz de Heredia, de ilustre prosapia, no tiene ni idea de lo que es dirigir un texto como ése. Así le ha salido la prueba.» ${ }^{36}$

En 1989, Lázaro Carreter dedicó dos artículos a tratar el título ¡Viva lo imposible o el contable de estrellas! Su interés por rescatar esta obra de Mihura se debe fundamentalmente al auge que estaba sufriendo en esos momentos la obra del comediógrafo. Como el crítico indicó,

\footnotetext{
31 F. Lázaro Carreter, «La decente, de Miguel Mihura», Blanco y Negro, (25 de septiembre de 1988), p. 30.

32 F. Lázaro Carreter, «La decente, de Miguel Mihura», Blanco y Negro, (25 de septiembre de 1988), p. 30.

33 F. Lázaro Carreter, «La decente, de Miguel Mihura», Blanco y Negro, (25 de septiembre de 1988), p. 30.

34 F. Lázaro Carreter, «La decente, de Miguel Mihura», Blanco y Negro, (25 de septiembre de 1988), p. 30.

35 F. Lázaro Carreter, «La decente, de Miguel Mihura», Blanco y Negro, (25 de septiembre de 1988), p. 30.

36 L. López Sancho, «La decente, digna de compasión, en el Cómico», ABC, (14 de mayo de 1988), p. 90.
} 
la figura de Mihura se agranda con el paso del tiempo, y nada suyo debe caer en el olvido. Apelé, por ello, a Joaquín Calvo Sotelo, que gentilmente me ha proporcionado una fotocopia de la única y ya rara edición que se hizo de la comedia (Madrid, Gráficas Cinema, 1951). Ha sido un espléndido regalo de Reyes, y deseo compartir mi alegría con mis lectores. ${ }^{37}$

Gracias al repunte del interés por Mihura, de manera inteligente el profesor aprovecha la situación para abogar por la reposición de dicho texto:

La comedia rezuma poesía triste, menos pura, más fácil de comprensión - ¿significaría eso 'burguesa'?- que otras obras de Joaquín y, sobre todo, de Miguel, pero creo que, en 1989 alcanzaría el éxito que 1939 le negó. ¿No podría abrirse paso la reposición entre tantos insustanciales vodeviles? ${ }^{38}$

Sin embargo, esta sugerencia no fue un impedimento para que el crítico señalara la ambigüedad ${ }^{39}$ que, desde su punto de vista, planteaba la comedia:

Me sigo preguntando sobre el sentido de ¡Viva lo imposible! a la altura de aquella misérrima posguerra, y lo encuentro equívoco. En el acto primero invitaba a huir de una circunstancia donde sólo se podía aspirar a sobrevivir, en medio de una catástrofe. Pero cuando se presencia el resultado de aquella huida, y los personajes han logrado evadirse a la vida libre pero sin garantías que el circo simboliza, se les encuentra rodeado de gente sorprendente de cuyo ideal es la mediocridad. Y a Eusebio aferrado a su Despacho Administrativo, y a Palmira cediendo a los amores del vigoroso Fede, domador de leones, que sueña con una casta de cretonas y brasero. La que al fin, tendrá la muchacha, casada con el sórdido Vicente.

Es decir: si algún espectador no rechazaba los exhortos de don Sabino, y lo seguía con el alma en su vuelo imaginativo, se topaba desde el acto segundo con la decepción, con el fracaso de aquel sueño. ${ }^{40}$

La tetera se estrenó el 16 de noviembre de 1991 el teatro Cómico. La obra estuvo dirigida por Antonio Díaz Merat e interpretada por Maruja Carrasco, Pedro Valentín, Pedro Peña o María Recio, entre otros. Como explicó Lázaro Carreter,

posee todos los ingredientes que han situado a Mihura en la primera fila del teatro contemporáneo: humor, poesía, trama intrigante, limpieza, situaciones originales, personajes cautivadores... La tetera es, sin duda, una secuela de Maribel y la extraña familia. Razón de más para que sus innumerables admiradores sientan curiosidad por esta otra comedia. ${ }^{41}$

37 F. Lázaro Carreter., « $¡$ Viva lo imposible! o el contable de estrellas (I)», Blanco y Negro, $(8$ de enero de 1989), p. 12.

38 F. Lázaro Carreter, « ¡Viva lo imposible! o El contable de estrellas (II)», Blanco y Negro, (15 de enero de 1989), p. 12.

39 Según Arturo Ramoneda, «Mihura cultiva aquí un teatro evasivo, ingenioso y artístico, defensor de la libertad individual, pero de espaldas a las miserias de la España de posguerra», M. Mihura, Teatro completo, A. Ramoneda (ed.), Madrid, Cátedra, 2005, p. 42.

40 F. Lázaro Carreter, « ¡Viva lo imposible! o El contable de estrellas (II)», Blanco y Negro, (15 de enero de 1989), p. 12.

41 F. Lázaro Carreter, «La tetera», Blanco y Negro, (26 de enero de 1992), p. 12. 
Lázaro Carreter se congratuló de su estreno: «No es una de las más frecuentes comedias de aquel admirable autor, continúa muy viva, y algo que no sean vodeviles necesitan los intérpretes especializados en hacer reír si no quieren perecer.» ${ }^{42}$ Otros críticos, como Lorenzo López Sancho $(A B C)$ también entendieron como algo positivo el estreno de la obra, en la que el teatro de Mihura ya ha alcanzado un alto grado de madurez y permite apreciar todo su valor. Don Fernando señaló las virtudes de la obra: «Estructura cómica de primer orden. Diálogo lleno de naturalidad, de verismo y a la par de malicia de retranca coloquial muy de los momentos mejores de Mihura, hacen de La tetera casi un 'thriller', así, españolizado, de carcajadas.» ${ }^{43}$ En la misma línea se encuentra el juicio de Alberto de la Hera $(Y a)$, que defendió lo siguiente «tiene mucha gracia. A base de situaciones llenas de ingenio, de un diálogo chispeante y sorprendente, de continuos juegos de palabras y sorpresas el autor consigue hacernos pasar un rato muy entretenido.» ${ }^{44}$ Por lo tanto, la crítica se mostró complacida ante este nuevo estreno.

Tres sombreros de copa se estrenó el 26 de septiembre de 1992 en el teatro Español. Fue dirigida por Gustavo Pérez Puig e interpretado por Luis Prendes, Félix Navarro, Paloma Paso, Nicolás Romero y Vicente Haro, entre otros. Para Fernando Lázaro Carreter, Gustavo Pérez Puig

ha hecho bien en echar mano de la admirable comedia, que el autor mismo le dedicó agradecido en la susodicha edición de Castalia; nadie podía apelar a ella con mejores títulos. Y pocos textos podían contar con mejores razones para servir de arranque a la nueva temporada en el Español. ${ }^{45}$

Pese a esto, hay que reconocer que «no es [...] solución óptima ésta de apelar a clásicos o a viejos prestigios modernos como base única, o casi, de programación, pero la sequía que padece la creación teatral obliga a los directores a alumbrar aguas antiguas.» ${ }^{46}$ De hecho, nuevamente, el crítico apuntaba el fin comercial como principal criterio de selección de la programación:

Sesenta años hace que Mihura escribió Tres sombreros de copa; cuarenta que fue estrenada... Y, además, al frente del teatro Español, la misma persona que, allí mismo, en plena mocedad, había planeado el alumbramiento escénico de la criatura...: ¿ ¿ómo iba resistir Pérez Puig tanta congregación de eventos, auspiciada por el sistema métrico decimal y el anejo y creciente culto a los números redondos? ${ }^{47}$

\footnotetext{
42 F. Lázaro Carreter, «La tetera», Blanco y Negro, (26 de enero de 1992), p. 12.

43 F. Lázaro Carreter, «La tetera», Blanco y Negro, (26 de enero de 1992), p. 12.

44 A. de la Hera, «Una tetera divertida», Ya, (16 de noviembre de 1991), p. 63.

45 F. Lázaro Carreter, «Nueva temporada en el Español», Blanco y Negro, (13 de septiembre de 1992), p. 14.

46 F. Lázaro Carreter, «Nueva temporada en el Español», Blanco y Negro, (13 de septiembre de 1992), p. 14.

47 F. Lázaro Carreter, «Nueva temporada en el Español», Blanco y Negro, (13 de septiembre de 1992), p. 14.
} 
El estreno del teatro Español complació a Lorenzo López Sancho $(A B C)$ que afirmó: «Alcanza el teatro ese punto de elocuente perfección y madurez en todos los complementos, vestuario, movimientos de conjunto, escenas complementarias en que se cuaje una pieza llena de talento, de audacia descriptiva, de sonrientes ironías críticas.» ${ }^{48}$ A la par que se consigue respetar la obra del autor: «Miguel Mihura, vivo, joven, atrevido, innovador y sonriente estaba anoche, como hace ya tantos años, en la noche de su estreno. La personalidad inconformista, ingeniosa, atrevida del viejo amigo, vibraba anoche en este ejemplar montaje del teatro español.» ${ }^{49}$

El propio autor comprendía las innovaciones que planteaba su obra y la necesidad de que pasara el tiempo para que ésta pudiera conocer el éxito. Como puntualizó Lázaro Carreter:

Hacia 1957, el autor declaraba que habría de pasar mucho tiempo antes de que Tres sombreros de copa fuera una obra normal en España. Vamos a tener ocasión de comprobar si ya ha pasado todo ese tiempo previsto por Mihura o aún no. El curso que siga la comedia en el coliseo de la plaza de Santa Ana va a constituir un 'test' muy interesante sobre nuestro público..$^{50}$

Mihura se sitúa dentro del importante grupo de dramaturgos de posguerra. ${ }^{51}$ Así lo encuadra Lázaro Carreter:

A uno de esos clanes, orientado hacia el humor -de ahí su encandilamiento con Gómez de la Serna- y atraído por el mundo del espectáculo, perteneció Mihura. Con López Rubio, Neville, Calvo Sotelo, Tono y, algo menos homogéneo, Jardiel. [...] Nada les gusta más a aquellos muchachos que desconectar a tenderos y notarios. Y agotar hasta el fondo su libertad, no pocas veces disparatada. ${ }^{52}$

El autor aspiraba a obtener un reconocimiento. Como explica Lázaro Carreter, Mihura pretendía presentar otro humor radicalmente diferente al que triunfaba en esos momentos:

La audacia de Mihura consistía, claro es, en pretender que su obra pudiera hacerse un hueco en la escena hilarante de aquel momento, dominada por el astracán. Han tenido que pasar muchas cosas -entre otras, La Codorniz- para que se refinara el

48 F. Lázaro Carreter, «Tres sombreros de copa», Blanco y Negro, (27 de septiembre de 1992), p. 12.

49 F. Lázaro Carreter, «Tres sombreros de copa», Blanco y Negro, (27 de septiembre de 1992), p. 12.

50 F. Lázaro Carreter, «Nueva temporada en el Español», Blanco y Negro, (13 de septiembre de 1992), p. 14.

51 Como ha indicado Jorge Rodríguez Padrón, es precisamente por Tres sombreros de copa, por la obra por la que Mihura ha encontrado un lugar destacado en el teatro de posguerra: «Miguel Mihura, a los cuarentra y cinco años de esta comedia, con ella y por ella, sigue siendo una figura clara de nuestro teatro actual [...] Casos como el de Miguel Mihura y Tres sombreros de copa han sido hasta ahora excepcionales en el discurrir de nuestro teatro». M. Mihura, Tres sombreros de copa, J. Rodríguez (ed.), Madrid, Cátedra, 1985, pp. 63-64.

52 F. Lázaro Carreter, «Tres sombreros de copa», Blanco y Negro, (27 de septiembre de 1992), p. 12. 
sentido del humor, hasta el punto de que nuestro primer coliseo se llene a diario y el público ría y aplauda con fervor..$^{53}$

Además de buscar cambiar las características cómicas de la época, el teatro de Mihura tiene una profundidad temática que le permite sobrevivir muchos años después del momento en el que fue creado: «Una vez remozada la percepción de lo cómico, el fondo sentimental que recorre la comedia como un bajo continuo, y al que tan de grado se rinde al público de los teatros, explica el éxito en que ha acabado por convertirse el triunfo del estreno.. ${ }^{54}$

Al explicar los mecanismos del humor de Mihura, Lázaro Carreter no dejó pasar la oportunidad para separarlo del teatro del absurdo, equivocación que como subraya el crítico, se comete con frecuencia por parte de los investigadores. Afirmó que «supone una alteración situar a Miguel Mihura en la órbita del teatro del absurdo, es decir, en la vecindad de Ionesco.» ${ }^{55}$ Aunque este marbete se ha utilizado y se sigue utilizando para designar al teatro de algunos de los humoristas del círculo de Mihura, nos encontramos ante una grave equivocación, puesto que los planteamientos ideológicos del teatro del absurdo se encontraban muy alejados de los del grupo de nuestros comediógrafos. Sobre este aspecto, arroja mucha luz la explicación propuesta por Emilio de Miguel, que engloba también lo que sucedió con las obras del resto de dramaturgos del grupo:

En el teatro de Mihura, y con particular intensidad durante su primera época, abundan las transgresiones al sistema lógico en las ocurrencias y modos de ser de muchos de sus personajes, pero como audacias dispersas [...] El absurdo se domestica, produciéndose un entrecruce de planos que, lejos de forzar el argumento a seguir pautas absolutamente dislocadas, lo hace discurrir por cauces extraños, inesperados, pero no tildables de absurdos; calificables, quizá, de realismo imposible. ${ }^{56}$

\section{Como explicó Lázaro Carreter,}

[1]as palabras son culpables de muchas equivocadas relaciones entre las cosas. Por ejemplo: el vocablo absurdo, que se asoció con un tipo de teatro de gran acogida intelectual hace unos cuarenta años, del que Beckett (inquietante), Ionesco (ingenioso) y Adamov (pelma) fueron exponentes máximos. Apenas ese teatro asomó por Madrid, surgieron gestos de decepción por su carencia de novedad, pues aquello, se decía, ya lo había hecho Mihura en algunas de sus comedias más tempranas, en especial en Tres sombreros de copa. ${ }^{57}$

Sucedió lo siguiente:

53 F. Lázaro Carreter, «Tres sombreros de copa», Blanco y Negro, (27 de septiembre de 1992), p. 12.

${ }^{54}$ F. Lázaro Carreter, «Tres sombreros de copa», Blanco y Negro, (27 de septiembre de 1992), p. 12.

55 F. Lázaro Carreter, «Mihura y el absurdo», Blanco y Negro, (20 de septiembre de 1992), p. 14.

56 M. Mihura, Maribel y la extraña familia, E. de Miguel (ed.), Madrid, Espasa Calpe, 2006, pp. 52-53.

57 F. Lázaro Carreter, «Mihura y el absurdo», Blanco y Negro, (20 de septiembre de 1992), p. 14. 
Este adjetivo creó la confusión: puesto que, en gran medida, son absurdos en el sentido ordinario del término, situaciones y diálogos de la comedia, y no lo es menos lo que pasa y se dice en obras que venían de París, bastó eso para poner la nuestra delante de todas en el mismo pelotón con el banderín de precursora. Se confundieron, y se siguen confundiendo, los valores adjetivo y sustantivo del vocablo absurdo.

Algo contribuyó a la confusión el propio Ionesco, que, opinando sobre la comedia, señalaba cómo el ridículo a que apela Mihura realza la verdad de las cosas, y descubre mejor que un tratamiento racional o dialéctico «las contradicciones del espíritu humano, la estupidez, el absurdo».

No hay duda; pero eso no autoriza a colocar Tres sombreros de copa ni en la historia ni en la estela del «teatro del absurdo». ${ }^{58}$

Como se ha podido comprobar, la valoración de la obra de Mihura bajo la mirada de Lázaro Carreter es positiva. Considera que las innovaciones humorísticas que se filtran en sus páginas fueron muy novedosas y adelantadas para el momento en el que se escribieron. Incluso admite que han necesitado años para ser entendidas y aceptadas por un público mayoritario. Por tanto, su estima hacia la obra de Mihura resulta evidente.

\section{CONCLUSIONES}

Como se ha podido comprobar en estas páginas, el interés de Lázaro Carreter por el teatro fue máximo. Esto se puede deducir de la lectura de las crónicas periodísticas que publicó durante varios años semanalmente, además de por su importante labor investigadora en dicho campo. En este trabajo se han podido presentar sus valoraciones sobre los estrenos de Jardiel Poncela y de Miguel Mihura. Ha quedado puesto de manifiesto que don Fernando era un buen conocedor de la obra de estos dramaturgos y que sentía un gran afán por estudiar y difundir los fundamentos humorísticos del grupo teatral al que pertenecían.

Como ha quedado patente, en la inmensa mayoría de las ocasiones, Lázaro Carreter coincidía con el criterio de otros especialistas, manteniéndose en consonancia con ellos. Del mismo modo, en este breve estudio ha quedado reflejado que su preferencia se encontraba claramente en el teatro de Mihura, que describía más maduro y logrado que el de Jardiel, sin desmerecer los logros del escritor madrileño. Por tanto, se ofrecen materiales periodísticos de primera importancia, que nos acercan a una de las facetas más destacadas del pensamiento lazariano.

58 F. Lázaro Carreter, «Mihura y el absurdo», Blanco y Negro, (20 de septiembre de 1992), p. 14. 


\section{Bibliografía}

Álvaro, F., El espectador y la crítica. El teatro en España en 1972, Madrid, Prensa española, 1980.

Arroyo, L., Crítica literaria y creación teatral en Fernando Lázaro Carreter. Dirección Andrés Amorós y Santiago López-Ríos, Madrid, Universidad Complutense de Madrid, 2013. (Tesis doctoral)

BlesA, T., «Fernando Lázaro Carreter: la literariedad de la literatura», Anexos de Tropelías, 12, Zaragoza, Universidad, 2007, pp.43-64.

Bruguera Nadal, M. L., «El teatro cómico: de Jardiel a Paso», en J. Huerta (dir.), Historia del teatro español, II, Madrid, Gredos, 2003, pp. 2703-2729.

Cortázar, B., «Usted tiene ojos de mujer fatal, un clásico de la seducción», $A B C$, (16 de junio de 1989), p.147.

GALINDO, C., «Cuatro corazones con freno y marcha atrás, nuevo pálpito de Jardiel Poncela», $A B C$, (15 de diciembre de 1987), p. 101.

Haro TeCglen, E., «El principio de algo», El País, (25 de mayo de 1989), p. 87.

Haro Tecglen, E., «Jardiel, marcha atrás». El País, (18 de diciembre de 1987), p. 85.

Hera, A. de la, «Una tetera divertida», Ya, (16 de noviembre de 1991), p. 63.

Huerta Calvo, J., E. Peral Vega, y H. Urzáiz Tortajada, Teatro español: (de la A a la Z), Madrid, Espasa Calpe, 2005.

Jardiel Poncela, E., Usted tiene ojos de mujer fatal; Angelina o el honor de un brigadier, A. A. Gómez Yebra (ed.), Madrid, Castalia, 1990.

Jardiel Poncela, E., Cuatro corazones con freno y marcha atrás; Los ladrones somos gente honrada, F. Valls y D. Roas (eds.), Madrid, Espasa Calpe, 2000.

Jardiel Poncela, E., Amor se escribe sin hache, R. Pérez (ed.), Madrid, Cátedra, 2006.

Jardiel Poncela, E., Pero... ¿hubo alguna vez once mil vírgenes?, L. Alemany (ed.), Madrid, Cátedra, 2007.

LABORDA, Á., «En el Infanta Isabel: Maribel y la extraña familia», ABC, (2 de septiembre de 1978), p. 38.

LÁzaro Carreter, F., «Miguel Mihura», Gaceta ilustrada, (11 de diciembre de 1977), p. 83.

LÁZARo CARreter, F., «Maribel y la extraña familia de Miguel Mihura», Gaceta ilustrada, (1 de octubre de 1978), p. 65.

LÁZARO CARRETER, F., «Angelina o el honor de un brigadier», Gaceta ilustrada, (11 de febrero de 1979), p. 52.

LÁzaro Carreter, F., «Una comedia de Jardiel», Gaceta ilustrada, (3 de junio de 1979), p. 74.

LÁzARo CARreter, F., «Cuatro corazones con freno y marcha atrás», Blanco y Negro, (10 de abril de 1988), p. 12. 
LÁzaro Carreter, F., «La decente, de Miguel Mihura», Blanco y Negro, (25 de septiembre de 1988), p. 30.

LÁzaro Carreter, F., « ¡Viva lo imposible! o el contable de estrellas (I)», Blanco y Negro, (8 de enero de 1989), p. 12.

LÁZARo CARreter, F., «iViva lo imposible! o El contable de estrellas (II)», Blanco y Negro, (15 de enero de 1989), p. 12.

LÁzaro Carreter, F., «Usted tiene ojos de mujer fatal, de Jardiel Poncela», Blanco y Negro, (9 de julio de 1989), p. 12.

LÁzAro CARreter, F., «La tetera», Blanco y Negro, (26 de enero de 1992), p. 12.

LÁzaro Carreter, F., «Nueva temporada en el Español», Blanco y Negro, (13 de septiembre de 1992), p. 14.

LÁzaro CARreter, F., «Tres sombreros de copa», Blanco y Negro, (27 de septiembre de 1992), p. 12.

LÁZAro CArreter, F., «Mihura y el absurdo», Blanco y Negro, (20 de septiembre de 1992), p. 14.

López Rubio, J., «La otra generación del 27»: discurso leído el cinco de junio de 1983, Madrid, Real Academia Española, 1983.

LóPEZ SANCHO, L., "Cuatro corazones con freno y marcha atrás, kamikace cómico en el Maravillas», ABC, (18 de diciembre de 1987), p. 104.

López SANCHO, L., «La decente, digna de compasión, en el Cómico», ABC, (14 de mayo de 1988), p. 90.

López SANCHO, L., «La tetera, con salsa dentro de Miguel Mihura, en el Cómico», $A B C$, (19 de enero de 1991), p. 101.

LóPEZ SANCHO, L., «Tres sombreros de copa, en una magistral interpretación de una obra maestra de Mihura», ABC, (20 de agosto de 1992), p. 77.

Minura, M., Tres sombreros de copa, Jorge Rodríguez Padrón (ed.), Madrid, Cátedra, 1985.

Minura, M., Maribel y la extraña familia, M. Mihura (ed.), Madrid, Castalia, 1997.

Minura, M., Teatro completo, Arturo Ramoneda (ed.), Madrid, Cátedra, 2005.

Minura, M., Maribel y la extraña familia, E. de Miguel (ed.), Madrid, Espasa Calpe, 2006.

RuIz RAMÓN, F., Historia de la literatura española. Siglo XX., Madrid, Cátedra, 1986.

SAHUQuillo VAlLejo, F. J., «El olvidado inverosímil: aproximación a la figura de Enrique Jardiel Poncela», en VVAA., No es país para jóvenes. Actas de la Asociación de Historia Contemporánea, Instituto Valentín de Foronda, Universidad del País Vasco, 3 (2012). 